\title{
VEGETAÇÃO, PAISAGEM E O PLANEJAMENTO DO USO DA TERRA
}

\author{
Claudio Belmonte de Athayde Bohrer \\ Universidade Federal Fluminense
}

\section{Introdução}

A terra, incluindo atributos como água, solo, litologia e vegetação, pode ser considerada talvez como o principal recurso disponível para o desenvolvimento econômico em regiões tropicais. No planejamento do uso do solo, os diversos atributos da terra são analisados e avaliados com vistas a um uso ótimo e sustentável. As principais informações requeridas sobre esses atributos são a sua distribuição espacial, os padrões (forma e arranjo das unidades de recursos) e o tipo de recurso. A análise dos padrões atuais de uso do solo e dos fatores econômicos e sociais que afetam o uso do solo também são importantes no processo de planejamento.

Diversas metodologias e procedimentos vêm sendo desenvolvidos e aplicados na análise dos recursos naturais, permitindo diversos níveis de enfoque, de acordo com as necessidades dos responsáveis pela tomada de decisões. Em geral, estes métodos possibilitam comparar diversas alternativas de uso dos recursos naturais com base na análise de diferentes cenários, advindos da adoção de cada uma das possíveis alternativas.

Este trabalho tem por objetivo revisar alguns dos procedimentos usuais de avaliação utilizados no planejamento do uso da terra, e avaliar até que ponto aspectos importantes relacionados à vegetação natural, especialmente em áreas com cobertura florestal, são incorporados nesses procedimentos. Os diversos aspectos sociais, culturais, econômicos e políticos, não tratados aqui, bem como a participação das comunidades envol- 
vidas e da sociedade nas diferentes etapas do processo, são igualmente importantes para o planejamento visando o uso sustentável da terra e da floresta em particular. Entretanto, é necessário ampliar a discussão e reavaliar ampla e continuamente os diversos procedimentos técnicos utilizados na análise e avaliação dos possíveis potenciais ou aptidões das terras para diferentes tipos de uso, tema geralmente restrito a um pequeno número de técnicos e pesquisadores ligados ao setor de planejamento.

\section{Avaliação das Terras}

A avaliação das terras utiliza as características e/ou qualidades obtidas na análise do terreno, juntamente com outras propriedades, para atribuir um valor a um trato de terra. É um procedimento que informa ao planejador sobre as relações entre as alternativas existentes. A classificação das terras em unidades homogêneas é um aspecto fundamental em qualquer levantamento e avaliação (TROUBER et al., 1989).

A terra, ou mais especificamente, o conceito de terra, pode ser interpretada de diferentes formas, conforme o enfoque adotado. Uma definição tradicional considera uma unidade de terra como "uma área da superfície terrestre cujas características abrangem todos os atributos estáveis ou de ciclo previsível da biosfera, verticalmente acima ou abaixo desta área, incluindo a atmosfera, o solo e a rocha matriz, a hidrologia, as populações animais e vegetais, e os resultados de atividades humanas passadas e correntes, na medida em que tais atributos influenciam o uso atual e futuro da terra pelo homem" (FAO, 1976).

Geralmente na avaliação das terras, as características das diferentes unidades de terra (U.T.) são confrontadas com os requerimentos exigidos por diferentes tipos de uso da terra (T.U.T.) considerados relevantes, na avaliação da aptidão de cada U.T. para cada T.U.T (TROUBER et al., 1989). Um tipo básico de procedimento é atribuir um peso ou valor para os potenciais de uso ou produtividade, de acordo com o estado atual do recurso. Esta é uma avaliação que se baseia principalmente na capacidade natural, inerente ou intrínseca da terra, de suportar um determinado tipo de uso. Um tipo alternativo de avaliação valoriza a habilidade potencial de um recurso de produzir bens e serviços, com base na produção máxima possível para um determinado tipo ou nível alternativo futuro de insumo no manejo da terra.

O processo de valorização geralmente é executado por uma equipe multi-disciplinar, com conhecimento e experiência nos tipos de uso ou atividades avaliados, em ecologia e nos processos de degradação e práticas de uso da terra, bem como conhecimento da realidade sócio-econômica da área avaliada. Os usos atuais do solo podem determinar a exclusão, no planejamento a curto prazo, da aptidão para outros tipos de uso. As condições sócio-econômicas por sua vez irão pesar na análise dos níveis de insumos a serem considerados. É um processo dinâmico que precisa ser reavaliado periodicamente, devido a novas evidências científicas, inovações tecnológicas e mudanças na realidade sócio-econômica. 
A aptidão ou capacidade das terras descreve a possibilidade do terreno de suportar um uso definido (FAO, 1976). É a descrição da unidades de terra em termos de sua capacidade inerente de suportar um dado tipo, intensidade e qualidade de uso, em bases sustentadas. É um método voltado principalmente para a agricultura, mas que pode ser relacionado a usos específicos (pecuária, silvicultura, conservação, etc.).

Carpenter (1981) revisou os procedimentos para a classificação da capacidade das terras tropicais com cobertura florestal, dividindo-os em quatro fases. A primeira é a fase de planejamento, quando o uso potencial dos resultados da classificação das terras é avaliado. A escala de avaliação é selecionada de acordo com os objetivos gerais, bem como a disponibilidade de material básico (mapas, imagens, etc.).

A segunda fase é a coleta de informações, que objetiva estabelecer as unidades de terra ou de paisagem, relacionadas com os componentes básicos do ecossistema: geologia, topografia e forma do relevo, clima, solo e vegetação. Devido à grande importância do clima para as atividades relacionadas ao uso da terra, é comum a produção de mapas mostrando as diversas zonas bioclimáticas, geralmente associadas a diagramas climáticos (HOLDRIDGE, 1971; MUELLER-DOMBOIS, 1981; WALTER, 1985). Outras informações temáticas podem ser recuperadas a partir de mapas já existentes ou levantadas em estudos específicos.

A terceira fase compreende a análise integrada e redução dos dados, e a elaboração de relatórios e mapas numa escala comum. O estabelecimento das unidades de terra pode requerer alguma abstração, devido às diferenças nos limites das diferentes unidades temáticas nos diversos mapas utilizados. Os componentes individuais da paisagem podem ser organizados de forma hierárquica. Um enfoque adequado para delinear-se unidades com diferentes potenciais biológicos pode ser a seleção das formações vegetais, que são relativamente estáveis sob condições naturais. Em mapas a nível de detalhe, pode ser utilizada uma síntese dos dados obtidos em pontos de amostragem do habitat físico e da vegetação.

A quarta fase é a apresentação e transferência das informações. Numa escala regional, os possíveis usuários incluem primariamente os administradores ou responsáveis pela alocação de terras, bem como agricultores ou empresários rurais, pesquisadores, engenheiros agrônomos e florestais, zootecnistas, administradores de unidades de conservação, etc. A nível sub-regional ou de detalhe, é aconselhável a elaboração de um relatório condensando os dados obtidos no campo, caracterizando os diversos habitats florestais nas áreas de manejo, e especificando como os diferentes tipos florestais podem ser identificados.

As possíveis opções para terras florestais tropicais incluem retenção, modificação ou conversão para outros tipos de uso da terra. No planejamento a nível regional ou mesmo local, pode-se considerar apenas os tipos gerais de uso ou de atividades, tais como culturas anuais ou perenes, pastagens, reflorestamento, etc. Para áreas com cobertura de floresta tropical, Carpenter (1981) sugere a adoção de quinze tipos de 
utilização das terras (Tabela 1), com refinamentos a serem feitos de acordo com as condições locais.

TABELA 1. Tipos de Utilização das Terras

\section{A. Retenção em condições essencialmente naturais}

1. Proteção de bacias hidrográficas

2. Conservação biológica, reserva científica

3. Manejo da fauna silvestre, caça ou pesca

4. Recreação extensiva ao ar livre

B. Modificação - ainda floresta, mas com alterações na estrutura e composição florística

5. Manejo florestal intensivo - plantios de enriquecimento, controle de fogo e pestes, estradas

6. Manejo florestal extensivo - poucas (ou nenhuma) operações silviculturais

7. Agrossilvicultura - árvores florestais remanescentes, colheita, exploração e replantio, mais culturas anuais ou perenes, e pecuária

C. (Re)Criação de florestas - áreas não florestais e terras degradadas

8. Plantios florestais e reflorestamentos (revegetação ou restauração)

\section{Conversão para outros usos}

9. Agricultura - culturas anuais

10. Agricultura - culturas perenes

11. Agricultura irrigada

12. Pecuária intensiva - geralmente com re-semeadura, fertilizantes e pastagens melhoradas

13. Pecuária extensiva - pastagens naturais

14. Mineração superficial de areia, argila e cascalho

15. Construção de tanques para piscicultura e aquicultura

Fonte: adaptado de Carpenter (1981)

\section{Levantamento Integrado dos Recursos Naturais}

O levantamento integrado pode ser definido como uma combinação de levantamentos sobre diversos atributos da terra em um só procedimento. Alguns dos enfoques empregados em levantamento integrados de recursos naturais e ambientais, e na avaliação da aptidão das terras incluem estudos multi-disciplinares, com compilação ou reunião de estudos temáticos, estudos específicos (ex. zoneamento agrícola/florestal); estudos inter- ou trans-disciplinares, com utilização de um enfoque sistêmico (holístico), e de conceitos como geossistemas, sistemas de terra, de paisagem ou ecológicos (DAVIDSON, 1992; ZONNEVELD, 1995).

\section{O Componente Vegetação}

Na maioria dos estudos de avaliação do potencial das terras, os atributos da vegetação natural são enfocados de modo secundário, ou simplesmente ignorados 
(WEILL, 1990). Quando contemplados, geralmente os estudos concentram-se no potencial florestal para a produção de madeira para fins industriais ou energéticos (FAO, 1984; HEINSDIJK, 1975). A grande maioria dos levantamentos e respectivas avaliações de potencial das terras enfoca principalmente o potencial agrícola ou de extração de recursos minerais. A destinação de áreas com vocação para exploração florestal ou conservação baseia-se quase que exclusivamente no baixo potencial de utilização agrícola devido a limitações tais como relevo, fertilidade natural e dificuldades de drenagem, ou pela ausência de recursos minerais (RAMALHO \& BEEK, 1995). Em geral, as avaliações são baseadas em estudos multi-disciplinares, com os atributos vistos de forma particular e isolada, com pouca ou nenhuma integração entre as equipes técnicas.

Com o surgimento de críticas a esse tipo de procedimento, reforçadas por resultados controversos ou mesmo pelo fracasso de diversos projetos agrícolas e de colonização (EDEN \& PARRY, 1986), sugeriu-se o emprego de enfoques e métodos que permitissem um estudo integrado, holístico, inter ou trans-diciplinar, dos recursos ambientais. Conceitos provenientes principalmente da geografia física foram adotados e adaptados em diversos estudos, como uma tentativa de desenvolver metodologias que permitissem a obtenção desta visão holística, abrangente, do espaço natural (AZEVEDO, 1987; Brasil, 1990; COCHRANE et al., 1985). Entretanto, é difícil romper o isolamento e desenvolvimento particular de disciplinas que vêm há décadas estudando e detalhando o conhecimento sobre cada um dos atributos ou componentes do ambiente natural. Como resultado, a maioria dos estudos ainda enfatizam e priorizam os atributos do ambiente físico, notadamente clima, solo e relevo, e os processos morfo-pedológicos (D’AGOSTINI \& SCHLINDWEIN, 1998; TRICART \& KILLIAN, 1982). Os componentes biológicos, tais como a vegetação natural, geralmente são enfocados como agentes atuantes, através de processos como a fotossíntese e a transpiração, ou pela interceptação da chuva, em processos hidrológicos ou na formação de solos, ou indiretamente, associada ao manejo das terras. O seu valor intrínseco, ou seja, a sua biodiversidade, as inter-relações e os processos eminentemente ecológicos raramente são levados em conta.

\section{O Enfoque Holístico}

O conhecimento científico acumulado em diferentes ramos da ciência, bem como de estudos integrados que incorporam a ecologia e a teoria de sistemas, vem demonstrando as inter-relações entre as diferentes características do terreno (HUGGETT, 1995). O agrupamento das características e processos em uma localidade geralmente estende-se espacialmente, o que possibilita a sua regionalização. A partir de um limitado número de propriedades e observações, pode-se estimar muitas outras características e qualidades do ambiente natural. 
O enfoque holístico propõe, de forma geral, que a natureza seja estudada e avaliada de modo integrado, no qual os diversos componentes ou atributos são vistos não como porções segmentadas, mas como partes de um sistema complexo, interagindo entre si através de processos que atuam em diferentes escalas espaciais e temporais. $\mathrm{O}$ seu emprego permite aprimorar os resultados dos levantamentos de recursos naturais, possibilitando uma melhor compreensão das relações entre os diversos atributos da terra. O terreno é estudado como um objeto operacional, no lugar da investigação analítica ou em separado de suas partes componentes (ZONNEVELD, 1995).

As principais propriedades e características diagnósticas (componentes ou atributos) das unidades de terra (ecológicas, de paisagem ou ambientais) geralmente incluem uma classificação hierárquica corológica ou espacial (unidade, sistema, paisagem), o funcionamento e dinâmica da paisagem (fluxos de matéria, energia e informação, evolução e mudanças temporais), métodos e ferramentas de análise (levantamento de campo, amostragem, sensoriamento remoto, sistemas de informações geográficas, modelos ambientais/ecológicos, análise estatística) e a integração com dados sócio-econômicos.

O conceito de terra pode abranger todas as características do ambiente físico (atmosfera, solo, geologia, hidrologia, fauna e flora), ser considerado como o espaço tridimensional onde vive o homem, como bem de consumo, locação, propriedade ou forma de capital, ou sob o ponto de vista ecológico, definido em termos de ecossistema (DAVIDSON, 1992). De certa forma é um conceito homólogo ao geossistema (MONTEIRO 2000; Passos, 1998; SOTCHAVA, 1977), geralmente considerado como uma unidade funcional que associa elementos diferentes (mosaico), ou uma associação de unidades geomorfológicas (geofácies). O mapeamento de geossistemas ou unidades de terra, objetiva a subdivisão da terra em unidades ecológicas relativamente homogêneas, caracterizadas por um conjunto de atributos que são a expressão tangível do ecossistema (ZONNEVELD, 1995).

\section{Análise da Paisagem}

Dansereau (1957) propôs o estudo da paisagem como o nível integrativo mais alto dos processos e relações ambientais. O enfoque holístico considera o papel do homem como parte integrante de um nível mais alto do ecossistema, operando na paisagem. $\mathrm{O}$ uso de métodos orientados para a paisagem e a integração dos dados sobre diferentes atributos em sistemas de informações geográficas pode melhorar consideravelmente a utilização de dados provenientes de levantamentos de vegetação no planejamento do uso da terra.

A ecologia da paisagem (geoecologia) pode ser considerada como uma ciência que combina o enfoque regional da geografia no exame das inter-relações espaciais dos fenômenos naturais com o enfoque vertical da ecologia, no estudo das inter-relações funcionais em um dado sítio ou ecotopo (NAVEH \& LIEBERMAN, 1984; TROLL, 
1950; VINK, 1983). A paisagem pode ser definida como "uma porção espacial da superfície da terra constituída por um complexo de sistemas, formados pela atividade de rochas, água, ar, plantas, animais e o homem, reconhecível através de sua fisionomia como uma unidade" (ZONNEVELD, 1995), "uma área heterogênea de terra, uma unidade distinta e mensurável definida por um grupo reconhecível e espacialmente repetitível de ecossistemas interatuantes, geomorfologia e perturbações" (FORMAN \& GODRON, 1986). Resumindo, uma paisagem pode ser considerada como um grupo (cluster) de tipos de ecossistemas, sob a influência de um mesmo tipo de clima, geomorfologia (relevo) semelhante, com um conjunto semelhante de regime de perturbações e a ocorrência de fluxos ou interações através dos ecossistemas.

Uma unidade de paisagem pode ser considerada como "uma porção do espaço caracterizada por um tipo de combinação dinâmica de elementos geográficos diferenciados - físicos, biológicos e antrópicos, que ao enfrentarem-se dialeticamente uns com os outros, fazem da paisagem um 'conjunto geográfico' indissociável que evolui em conjunto, tanto sob o efeito de interações entre os elementos que a constituem como da dinâmica própria de cada um dos elementos individuais" (BERTRAND, 1968).

Estas definições de paisagem e unidade de paisagem remetem aos conceitos de terra e geossistema. Zonneveld (1995) considera unidades de terra (land unit) ou de paisagem (landscape unit) como sinônimos, independentes da escala de análise. Se considerarmos o geossistema como a dimensão espacial ou terrestre do ecossistema (igualmente um conceito independente de escala), a paisagem poderia ser definida então como um mosaico de geossistemas, ou seja, o geossistema equivale a uma unidade de paisagem (ecossistema), e não à paisagem como um todo (mosaico de ecossistemas). Huggett (1998) propõe a adoção do termo geoecossistema como equivalente ao conceito de paisagem. É necessária uma avaliação crítica das relações entre esses conceitos para a sua utilização de maneira clara e concisa, no estudo integrado da paisagem.

A paisagem deve ser analisada como um sistema ou entidade holística, composta por diferentes elementos, cada um influenciando os outros (KÜCHLER \& ZONNEVELD, 1988). A análise sistêmica tenta medir o grau de correlação entre os seus vários componentes. O enfoque estuda as relações verticais (topológicas) entre os elementos da comunidade ecológica e a sua distribuição espacial, levando em consideração o fluxo de energia e materiais e as mudanças ao longo do tempo, indicando uma certa evolução da paisagem. A dinâmica atual determina certos aspectos do ambiente, enquanto que dinâmicas passadas deixam uma herança no ambiente, afetando a sua susceptibilidade. A descrição da paisagem baseia-se na identificação e descrição de partes homogêneas ou unidades da paisagem, através da adoção de uma hierarquia de unidades.

Um mapa da paisagem pode ser considerado como um modelo analógico que representa a diferenciação espacial de um trato de terra. Mapas ecológicos da paisagem geralmente incluem pelo menos três atributos principais da terra, a composição da vegetação e o uso da terra (VAN GILS, 1989). O enfoque mais utilizado no mapeamento da paisagem baseia-se na sobreposição e integração de atributos individuais ou 
mapas multi-disciplinares, mapeados simultaneamente na mesma escala ou não. Outro enfoque baseia-se na análise de imagens de sensoriamento remoto, na qual os atributos da terra são interpretados de modo integrado, trabalhando-se do geral para o específico. Um terceiro enfoque é utilizado em diversos sistemas de informações geográficas, onde uma grade pré-determinada é superposta em um mapa topográfico, e vários atributos da terra são amostrados em cada quadrado da grade (KÜCHLER \& ZONNEVELD, 1988).

A geologia e as formas do relevo são os aspectos dominantes nos mapas da paisagem ou de unidades de terra, e os tipos de vegetação e domínios estruturais dominam os mapas ecológicos da paisagem. Geralmente ambos os tipos de mapas possuem informações sobre solos, configuração do terreno, declividade, tipos de rochas, cobertura vegetal, uso da terra, etc. A maioria dos mapas da paisagem utiliza a forma do relevo, considerado como o componente mais estável da paisagem, como legenda de entrada, num nível hierárquico superior (VAN GILS, 1989).

\section{A Vegetação na Análise da Paisagem}

No planejamento com base na ecologia da paisagem, é dada uma grande ênfase à vegetação, considerada como representativa das inter-relações entre o clima, solos e a influência humana. Informações sobre a vegetação são consideradas essenciais no desenvolvimento de um sistema de informações, devido a sua influência sobre o manejo dos recursos, e a interação com os outros atributos da paisagem, uma vez que pode ser considerada como um indicador das características desses atributos (RITERS et al., 1997). O mapa de vegetação pode ser considerado então como uma base natural para o levantamento ecológico da paisagem. Em áreas com forte influência antrópica, pode ser empregado o conceito de vegetação natural potencial (FRANKLLIN, 1995; KALKHOVEN \& WERF, 1988).

A vegetação pode ser usada ainda para indicar fatores não-mensuráveis ou nãomapeáveis, determinando-se empiricamente a correlação de dados ambientais com as comunidades vegetais ou tipos de vegetação, ou interpretando a estrutura da vegetação e das plantas individuais (formas de vida ou tipos funcionais) em termos de adaptação ao clima ou a padrões edáficos/hidrológicos (SALAS, 1987; ZONNEVELD \& SURASANA, 1988). O enfoque paisagístico fornece a possibilidade de extrapolação e interpolação de dados sobre o terreno com a vegetação e vice-versa. Dados adicionais sobre solos, relevo, hidrologia, etc., podem ser reunidos, correlacionando-se os dados de vegetação com os fatores ambientais, através de métodos como a ordenação multivariada ou análise de gradiente (JONGMAN et al., 1995).

A classificação da vegetação tropical varia de acordo com a escala e os objetivos do levantamento (BEARD, 1955; ELLEMBERG. \& MUELLER-DOMBOIS, 1967; UNESCO, 1973; VELOSO et al., 1991). Geralmente são utilizadas amplas classes estruturais da vegetação, pois a estrutura da vegetação é uma das principais fontes de 
informações em fotografias aéreas e em imagens de satélites (FOODY \& HILL, 1996; van GILS \& WIJNGAARDEN, 1984). Levantamentos a nível de reconhecimento ou semi-detalhe necessitam de uma tipificação detalhada da vegetação, incluindo indicações de sua composição florística e/ou das espécies dominantes, determinada através de amostragem de campo. O método mais preciso é através da observação direta em parcelas amostrais (inventário florestal ou florístico), procedendo-se a um tratamento estatístico dos dados de campo (KENT \& COKER, 1992; MUELLERDOMBOIS \& ELLEMBERG, 1974; TROUBER et al., 1989). Um modo prático é a utilização do enfoque paisagístico, pois mapeando-se as unidades de paisagem, os atributos desta, incluindo a vegetação, também serão mapeados (KENT et al., 1997). As unidades são utilizadas para estratificar a amostragem, podendo-se arranjar os pontos de observação em transects ou perfis, localizados em ecotonos para indicar transições graduais. A coleta de dados sobre os fatores ambientais pode ser empregada para o estabelecimento de correlações adicionais com a descrição da vegetação (JONGMAN et al., 1995; ZONNEVELD \& SURASANA, 1988).

Os mapas de vegetação e de uso da terra, combinados com mapas de outros atributos importantes (clima, geologia, relevo, solos), fornecem informações básicas essenciais para a avaliação da aptidão das terras. O mapa de vegetação apresenta um inventário das comunidades vegetais existentes, sua localização, extensão e distribuição geográfica na paisagem, servindo de ferramenta na análise do ambiente natural e das relações existentes entre a vegetação e o meio físico. As comunidades florísticas podem servir também como referência básica sobre a natureza do ambiente, como padrões de referência no monitoramento das mudanças temporais na vegetação, bem como de embasamento científico à adoção de sistemas silviculturais e agroflorestais, onde os solos florestais são manejados com vistas à produção sob bases sustentáveis e sem danos ao ambiente, bem como para a conservação de espécies e de habitats (BOOTH \& SAUNDERS, 1985; KÜCHLER \& ZONNEVELD, 1998; MEFFE \& CARROL, 1997).

\section{Exemplos de Levantamentos Integrados e Avaliação das Terras}

\section{Aptidão das Terras na Nova Zelândia}

Na avaliação da aptidão das terras na Nova Zelândia, são utilizados mapas de unidades de manejo das terras, caracterizadas inicialmente pelos seus atributos físicos, e posteriormente avaliadas pela aptidão de uso. O delineamento das unidades de mapeamento baseia-se nos atributos considerados de relevância permanente para o uso, como declividade, tipo de rocha e de solo. Subdivisões são feitas de acordo com a vegetação e o tipo e grau de erosão. Cada unidade é avaliada de acordo com a sua capacidade para o uso sustentado, de acordo com as limitações físicas, demandas de 
manejo e a necessidade de conservação do solo. As unidades são classificadas de acordo com o grau de limitação ao uso (DAVIDSON, 1992).

\section{Zoneamento Agroclimático}

Zoneamentos agroclimáticos baseiam-se no uso de dados climáticos obtidos em estações meteorológicas, extrapolados para a produção de mapas de variáveis individuais ou de classificações climáticas (Gaussen, Köppen, Thornthwaite, Penman \& Monteih), baseadas em dados como precipitação, temperatura, evaporação potencial, radiação, umidade do ar e velocidade dos ventos, e na relação entre clima e a vegetação natural ou culturas agrícolas. As variáveis utilizadas dependem das características da região, ou das necessidades específicas de culturas agrícolas. O enfoque pode ser adaptado para a definição e mapeamento de zonas ecoclimáticas (ecoregiões), definidas pela resposta ecológica ao clima, expressada pela vegetação e refletida nos solos, água e fauna silvestre. A análise de cenários futuros devido a mudanças climáticas é um dos possíveis usos em potencial deste enfoque (DAVIDSON, 1992; SCHUGART, 1998).

O enfoque agroclimático vem sendo amplamente utilizado no país, a nível regional e mesmo nacional, ou voltado para culturas específicas, como o trigo. Zoneamentos florestais, com ênfase na aptidão para plantios de espécies exóticas dos gêneros Pinus e Eucalyptus, também foram feitos a níveis estadual, regional e nacional, com base em mapas bioclimáticos (EMBRAPA, 1986; GOLFARI \& CASER, 1977; GOLFARI et al., 1978), podendo incluir ainda aspectos econômicos e relacionados à paisagem natural (GOLFARI \& MOOSMAYER, 1980).

\section{Sistemas de Terra - A Metodologia do CSIRO}

O enfoque de sistemas de terra foi desenvolvido na Austrália pelo CSIRO (Commonwealth Scientific and Industrial Organisation) para a coleta e utilização de informações na análise regional de opções da uso de terra. A metodologia empregada adota os conceitos de unidades de terra ou sistemas de terra no levantamento e avaliação das terras. O enfoque utiliza amostras (transects ou perfis) para estabelecer os elementos de terra e suas inter-relações, e as relações entre os padrões de terreno, através de uma taxonomia hierárquica, considerando os sistemas de terra como unidades corográficas determinadas pelo clima/paleoclima, litologia e história geomorfológica, as unidades de terra como áreas mais homogêneas que ocorrem repetidamente, com o fácies correspondendo a formas do terreno. Os dados de campo são utilizados para a descrição do sítio, definido como uma pequena área de terra considerada como representativa da morfologia do relevo (elementos e padrões), vegetação (fisionomia, estrutura e composição), superfície (aspecto, declividade, elevação, drenagem) e outras feições associadas com a observação do solo. O objetivo é um inventário que 
pode ser interpretado para uma ampla variedade de usos (DAVIDSON, 1992; PASSOS, 1998).

Uma limitação do enfoque é o uso de uma classificação multiatributo para avaliar as terras para um espectro de usos, o que depende de inter-relações e correlações complexas. Correlações observadas em um sistema de terra não são necessariamente válidas em outros sistemas ou regiões com atributos similares, ou seja, possuem um uso limitado para a classificação das terras e para extrapolações espaciais (TRICART \& KILLIAN, 1982). Idéias intuitivas e enfoques subjetivos são geralmente usados no agrupamento de unidades de mapeamento em sistemas de terra, não sendo utilizado um procedimento de amostragem estratificada explícito e consistente, elaborado de modo a garantir cobertura adequada de todos os tipos de paisagem (NAVEH \& LIEBERMAN, 1984).

\section{Avaliação da Paisagem - A Metodologia do ITC}

A metodologia de avaliação da paisagem desenvolvida no ITC (Holanda) faz a distribuição das unidades de paisagem no espaço em níveis hierárquicos de dimensões crescentes (KÜCHLER \& ZONNEVELD, 1988). O ecotopo é considerado a menor unidade holística de terra, caracterizada pela homogeneidade de pelo menos um atributo da geosfera, e com variações pequenas ou desprezíveis nos outros atributos. A faceta de terra (microcoro) é uma combinação de ecotopos, formando um padrão de relações espaciais, sendo fortemente relacionada a propriedades de pelo menos um atributo de terra, geralmente o relevo. O sistema de terra (mesocoro) é uma combinação de facetas de terra que formam uma unidade conveniente de mapeamento, em escala de reconhecimento. E, por fim, a paisagem principal (macrocoro) é conceituada como uma combinação de sistemas de terra, em uma determinada região geográfica.

A metodologia inclui dois aspectos da vegetação, sua composição e estrutura. As cartas de interpretação preliminar são utilizadas na estratificação da amostragem de campo, empregando-se uma combinação de diversas fontes de dados, tais como fotografias aéreas, imagens de satélite e mapas topográficos. Observações feitas nos pontos de amostragem incluem altitude; descrição das cores, textura e pH do solos; tipo, ângulo e exposição das encostas; e uso da terra. Os dados levantados sobre a vegetação incluem uma lista de todas as espécies vegetais, com uma estimativa da abundância e cobertura, em escalas padronizadas, e a coleta de material botânico das espécies desconhecidas para posterior identificação em herbário. Os dados florísticos são utilizados para fazer-se uma classificação ad hoc, de acordo com o método florístico de Braun-Blanquet (KÜCHLER \& ZONNEVELD, 1988).

A estrutura da vegetação é descrita através da estimativa da altura e cobertura dos estratos herbáceo, arbustivo e arbóreo, além de estimativas da área basal e biomassa entre as diferentes classes de altura, e da porcentagem do solo coberta pela serapilheira. O princípio é representar os valores de cobertura por estrato de vegetação numa 
forma especial, em duas ou três dimensões, utilizando-se a cobertura arbórea e arbustiva como características para diferenciar tipos de vegetação. A cobertura hídrica (estacionalidade) é a terceira característica. A combinação da cobertura total e da cobertura relativa por estrato resulta na tipificação estrutural da vegetação. A metodologia proposta pelo ITC vem sendo empregada com relativo sucesso em diversas regiões tropicais (KÜCHLER \& ZONNEVELD, 1988; LOTH \& PRINS, 1986; VAN GILS \& VAN WIJNGAARDEN, 1984).

\section{Sistemas de Informações Geográficas}

No planejamento do uso da terra, a integração na coleta de dados, análise espacial e o processo de tomada de decisões, num contexto de um fluxo comum de informações, pode ser feita através de um sistema de informações geográficas - SIG. Um SIG pode ser definido como um sistema digital para capturar, armazenar, recuperar, analisar e visualizar dados espaciais. SIGs podem ser utilizados como banco de dados ambientais, onde dados sobre os diferentes atributos da paisagem podem ser armazenados e manipulados (BURROUGH, 1986). Diferentes cenários podem ser analisados e avaliados, e os dados espaciais e/ou pontuais podem ser constantemente atualizados e combinados em novas análises.

Existem dois modos fundamentais de representar-se dados topológicos: a representação vetorial (pontos, linhas e polígonos, delineados por um conjunto de coordenadas) e em grade (raster, conjunto de células definidas pelas coordenadas $x$ e $y$ em um sistema de grade). Neste, cada célula (pixel) é independentemente endereçada com o valor de um atributo. A entrada dos dados é feita geralmente por digitalização ou por arquivos digitais. A estrutura da base de dados é na forma de uma série de mapas ou planos de informações, definidos por um mesmo sistema de coordenadas. $\mathrm{O}$ atributo é o valor de uma variável geográfica associada com uma dada posição topográfica. Os valores dos atributos podem ser transformados, usando-se procedimentos lógicos e matemáticos de combinação de diferentes atributos ou polígonos. A saída de dados pode ser feita na forma de mapas, gráficos e tabelas, ou arquivos digitais.

A principal vantagem do SIG é automatizar e agilizar a produção de mapas, com possibilidades de diferentes representações gráficas das informações e de rápida atualização. A possibilidade de analisar e comparar dados de mapas diversos, incluindo análises geoestatísticas, e de compilar novos mapas a partir da combinação de mapas armazenados é outra grande vantagem a ser considerada para a sua adoção no planejamento do uso da terra. Os SIGs tornam possível a criação de modelos dinâmicos sobre uma área, onde hipóteses sobre possíveis usos futuros da terra, os impactos de decisões do planejamento e as conseqüências dos processos naturais podem ser testados e avaliados. Entre os diversos tipos de análise espacial que podem ser feitos, incluem-se medições de áreas e perímetros, busca, classificação, modelagem cartográfica, overlay, redes, buffer (operações lógicas), distâncias (custo, difusão, proximidade), autocorrela- 
ção espacial (krigging), modelagem numérica de terreno, interpolação/extrapolação, padrão/dispersão, etc. (BURROUGH, 1986; CÂMARA \& MEDEIROS, 1996).

Com o rápido aumento da capacidade de processamento e redução do custo dos equipamentos, e a maior facilidade de integração entre os diferentes sistemas, treinamento de pessoal e manutenção do banco de dados, é crescente o uso dos SIGs em estudos ambientais e no planejamento (RAMALHO et al., 1997). É importante ressaltar que os resultados irão depender em grande parte da precisão dos dados originais, ou seja, a utilização de sistemas digitais não aumenta per si a precisão das análises.

Existe um grande potencial para a utilização de SIGs na conservação, manejo, zoneamento, monitoramento, exploração, e proteção florestal (fogo, vento, pragas, doenças, vigilância). Outras aplicações relevantes incluem análises de impactos e cenários, do processo de fragmentação florestal (efeito de borda, corredores, estrutura), na análise integrada e da dinâmica espacial da paisagem, em modelos de mudanças climáticas (processos, padrões espaciais e conseqüências), na pesquisa ecológica básica (dimensão espacial de processos eco-fisiológicos, distribuição espacial de populações e comunidades, transferência entre escalas), e no desenvolvimento de modelos florestais e ambientais espaciais (BITTENCOURT \& PIVELLO, 1998; HAINES-YOUNG et al., 1993; LAURANCE \& BIERREGARD-JR, 1997; McCLOY, 1995; SAMPLE, 1994; SCHUGART, 1998; TURNER. \& GARDNER, 1991).

A utilização de uso SIGs em estudos ecológicos proporciona um meio de conectarse o conhecimento de processos e mecanismos ecológicos, a partir de estudos de sítios, populações ou comunidades vegetais, com modelos de ecossistemas em diversas escalas espaciais e temporais, de auxiliar na locação de parcelas de estudos e/ou de áreas ecologicamente sensitivas, e de dar suporte à análise estatística de distribuições ecológicas (GOODCHILD et al., 1993). O uso do SIGs pode auxiliar também a melhorar a capacidade de extração de informações de imagens do sensoriamento remoto, através do uso de dados ambientais espaciais relacionados, como na análise de padrões espaciais de comunidades florestais e outros elementos da paisagem, cujos resultados podem ser importados e incorporados à base de dados.

SIGs são uma importante ferramenta na elaboração de mapas da vegetação potencial (FRANKLIN, 1995), ou seja, na previsão da composição e/ou estrutura da vegetação na paisagem a partir de variáveis ambientais mapeadas, ligadas à topografia (elevação, aspecto/exposição, posição na encosta), clima atual ou passado (precipitação, temperatura, radiação), solos (tipo, propriedades, elementos químicos), geologia (rocha matriz), hidrologia (bacia hidrográfica, altura do lençol, drenagem, escoamento superficial), etc.

\section{Conclusão}

Apesar da importância crescente conferida aos diversos valores, atuais e futuros, dos ecossistemas florestais tropicais, relacionados cada vez mais não só ao seu poten- 
cial de produção de madeira e de outros produtos não-madeireiros, mas também ao seu papel como habitat para uma grande diversidade de espécies vegetais e animais, proteção de solos e bacias hidrográficas, regulagem do clima a nível local, regional e global, lar e fonte de subsistência para uma grande população, ou até o seu valor intrínseco de existência, estes valores raramente são considerados na avaliação da aptidão das terras. Mesmo o papel da vegetação florestal como parte indissociável do ecossistema, resultado das inúmeras interações que ocorrem entre os seus componentes físicos e biológicos, muitas vezes simplesmente não é levado em conta, ou o é apenas parcialmente.

O crescente interesse na adoção de enfoques verdadeiramente holísticos, onde todos os principais componentes, incluindo o homem, são igualmente considerados como partes interatuantes e indissociáveis do ecossistema e da paisagem natural e cultural, indica uma mudança ocasionada em parte pelo crescente acúmulo de evidências científicas de que é praticamente impossível entender o funcionamento de um (eco)sistema apenas através do estudo segmentado de suas partes, ignorando-se as interações entre os diferentes componentes, físicos e biológicos. A necessidade de respostas urgentes para problemas ocasionados pelo manejo inadequado dos recursos naturais, e a pressão das comunidades afetadas e da sociedade como um todo para a reorientação do planejamento e para a implementação de medidas que efetivamente equacionem e solucionem estes problemas também vem funcionando como um catalisador na busca de enfoques integradores, na pesquisa aplicada e no planejamento, de forma a subsidiar, incentivar ou mesmo impor a adoção de propostas de manejo sustentável dos recursos florestais. Cabe aos pesquisadores, planejadores e tomadores de decisões responderem a essa demanda e anseio de modo efetivo.

\section{VEGETAÇÃO, PAISAGEM E O PLANEJAMENTO DO USO DA TERRA}

Resumo: O levantamento e mapeamento da vegetação vem tendo uma importância crescente no planejamento do uso da terra em regiões florestais tropicais. Os mapas de vegetação podem ser utilizados individualmente ou de forma integrada com outros mapas temáticos, para a caracterização e análise da paisagem, a qual serve de orientação no processo de planejamento do uso da terra. $\mathrm{O}$ uso de mapas ecológicos ou da paisagem contendo informações combinadas de diferentes atributos da paisagem, é um avanço significativo na avaliação das terras. O enfoque holístico possibilita uma melhor compreensão das inter-relações entre a vegetação e os outros atributos, melhorando significativamente as análises e avaliações resultantes . O enfoque paisagístico pode auxiliar ainda no próprio levantamento da vegetação, como o mapeamento dos diversos tipos de comunidades ou formações florestais de acordo com as características dominantes da ambiente físico, como o relevo. Sistemas de Informações Geográficas (SIG) vêm sendo cada vez mais utilizados como banco de dados ambientais, onde dados relevantes podem ser armazenados, manipulados, atualizados e combinados em diversas análises e avaliações de diferentes cenários de evolução dinâmica natural e antrópica da paisagem florestal tropical.

Palavras-Chave: Planejamento do Uso da Terra, Floresta Tropical, Análise da Paisagem, SIG 


\section{VEGETATION, LANDSCAPE AND LAND USE PLANNING}

Summary: The vegetation survey and mapping has an increasingly important role in the land use planning in tropical forest regions. Vegetation maps can be used individually or integrated with other thematic maps for the characterisation and analysis of the landscape, which will direct the land use planning process. The use of landscape ecological maps, which combine information from different land attributes is a significant advance on land evaluation and appraisal. The holistic approach allows a better understanding of the relationships between vegetation and other land attributes, which can improve considerably the results of the analyses and evaluation. The landscape approach can also improve the vegetation or forest survey, helping to map the different forest types according to the dominant aspects of the physical environment, such as relief. Geographical information systems (GIS) are increasingly used as a spatial environmental data base, where relevant data can be stored, handled, updated and combined in the analysis and evaluation of alternative scenarios of the natural and anthropogenic tropical forest landscape dynamics.

Keywords: Land Use Planning, Tropical Forest, Landscape Analysis, GIS.

\section{Bibliografia}

AZEVEDO, L.G. DE (1987) Ensaio Metodológico de Identificação e Avaliação de Unidades Ambientais: a Estação Ecológica de Pirapitinga-MG. SEMA/EMBRAPA-CPAC. Brasília.

BEARD, J.S. (1955) The classification of tropical American vegetation-types. Ecology 36: 89-100.

BERTRAND, G. (1968) Paysage et Géographie Physique Globale: esquisse méthodologique. Rev. Géogr. des Pyrenées et du Sud-ouest. 39: 249-272.

BITTENCOURT, M.C. \& PIVELLO, V.R. (1998) SIG e sensoriamento remoto orbital auxiliando o zoneamento ecológico. Investigaciones Geográficas Boletin 36: $35-43$

BOOTH, T.H. \& SAUNDERS, J.C. (1985) Applying the FAO Guidelines on Land Evaluation for Forestry. For. Ecol. And Management 12: 129-142.

BRASIL (1990) Diagnóstico Geoambiental e Sócio-Econômico: área de influência da BR-364 - trecho Porto Velho/Rio Branco. PMACI I. IBGE/IPEA. Rio de Janeiro.

BURROUGH, P. A. (1986) Principles of Geographical Information Systems for Land Resources Assessment. Oxford Univ. Press. Oxford.

CÂMARA, G. \& DE MEDEIROS, J.S. (1996) Geoprocessamento para Projetos Ambientais. INPE. São José dos Campos.

CARPENTER, P.A. (1981) Land capability classification: a procedure. In. Assessing Tropical Forest Lands: Their suitability for sustainable uses. Carpenter, P.A. (Ed.). Tycool International. Dublin. pp. 18-33.

COCHRANE, T.T., SÁNCHEZ, L.G., AZEVEDO, L.G. DE, PORRAS, J.A. \& GARVER, C.L. (1985) A Terra na América Tropical. CIAT/EMBRAPA-CPAC. Cali. 
D’AGOSTINI, L.R. \& SCHLINDWEIN, S.L. (1998) Dialética da Avaliação do Uso e Manejo das Terras. Ed. UFSC. Florianópolis.

DANSEREAU, P. (1957) Biogeography - An ecological perpective. Ronald, New York.

DAVIDSON, D.A. (1992) The Evaluation of Land Resources. Longman. ${ }^{\text {ed }}$. Harlow.

EDEN, M.J. \& PARRY, J.T. (1986) Remote Sensing and Tropical Land Management. John Wiley \& Sons. London.

ELLEMBERG, H. \& MUELLER-DOMBOIS, D. (1967) Tentative physiognomicecological classification of plant formations of the earth. Ber. Geobot. Inst. ETH, Stifz. Rubel. 37: 21-55.

EMBRAPA (1986) Zoneamento Ecológico para Plantios Florestais no Estado do Paraná. EMBRAPA-CNPF. Documentos, 17. Curitiba.

FAO (1976) Esquema para la Evaluación de Tierras. Boletin de Suelos FAO 32. Roma.

FAO (1984) Land Evaluation For Forestry. FAO Forestry Paper 48. Rome.

FOODY, G.M. \& HILL, R.A. (1996) Classification of tropical forest classes from Landsat TM data. Int. J. Remote Sensing 17: 2353-2376.

FORMAN, R.R.T. \& GODRON, M. (1986) Landscape Ecology. John Wiley \& Sons. New York.

FRANKLIN, J. (1995) Predictive vegetation mapping: geographic modelling of biospatial patterns in relation to environmental gradients. Progress in Physical Geography 19: 474-499.

GOLFARI, L. \& CASER, R.L. (1977) Zoneamento Ecológico da Região Nordeste para Experimentação Florestal. PNUD/FAO/IBDF/BRA-45. Série Técnica $\mathrm{N}^{\circ}$ 10. Belo Horizonte.

GOLFARI, L., CASER, R.L. \& MOURA, V.P.G. (1978) Zoneamento Ecológico Esquemático para Reflorestamento no Brasil. PNUD/FAO/IBDF/BRA-45. Série Técnica $\mathrm{N}^{\circ} 11$. Belo Horizonte.

GOLFARI, L. \& MOOSMAYER, H. (1980) Manual de Reflorestamento do Estado do Rio de Janeiro. BD-Rio. Rio de Janeiro.

GOODCHILD, M.F., PARKS, B.O. \& STAYERT, L.T. (1993) Environmental Modelling with GIS. Oxford Univ. Press. Oxford.

HAINES-YOUNG, R., GREEN, D.R. \& COUSINS, S.H. (1993) Landscape Ecology and Geographic Information Systems. Taylor \& Francis. London.

HEINSDIJK, D. (1975) Forest Assessment. PUDOC. Wageningen.

HOLDRIDGE (1971) The Forest Environment in Tropical Life Zones: A pilot study. Pergamon. New York.

HUGGETT, R.J. (1995) Geoecology - An evolutionary approach. Routledge. London. JONGMAN, R.H.G., TER BRAAK, C.J.R. \& VAN TONGEREN, O.F.R. (1995) Data Analysis in Community and Landscape Ecology. Cambridge Univ. Press. Cambridge. 
KALKHOVEN, J.T.R \& VAN DER WERF, S. (1988) Mapping the potential natural vegetation. In. Küchler, A.W. \& Zonneveld, I.S. (eds) Vegetation Mapping. Kluwer Academic. Dordrecht. pp. 375-386.

KENT, M. \& COKER, P. (1992) Vegetation Description and Analysis - A practical approach. John Wiley \& Sons. Chichester.

KENT, M., GILL, W.J., WEAVER, R.E. \& ARMITAGE, R.P. (1997) Landscape and plant community boundaries in biogeography. Progress in Physical Geography 21: 315-353.

KÜCHLER, A.W \& ZONNEVELD, I.S. (1988) Vegetation Mapping. Kluwer Academic. Dordrecht.

LAURANCE, W.F. \& BIERREGARD-JR, R.O. (1997) Tropical Forest Remnants: ecology, management, and conservation of fragmented communities. Univ. of Chicago Press. Chicago.

LOTH, P.E. \& PRINS, H.H.T. (1986) Spatial patterns of the landscape and vegetation of Lake Manyara National Park. ITC Journal 1986-2: 115-130.

MCCLOY, K.R. (1995) Resource Management Information Systems: process and practice. Taylor \& Francis. London.

MEFFE, G.K. \& CARROL, C.R. (1997) Principles of Conservation Biology. Sinauer. Sunderland.

MONTEIRO, C.A. DE F. (2000) Geossistemas: a história de uma procura. Contexto. São Paulo.

MUELLER-DOMBOIS, D. \& ELLEMBERG, M. (1974) Aims and Methods of Vegetation Ecology. John. Wiley \& Sons. London.

MUELLER-DOMBOIS, D. (1981) The ecological series approach to forest land classification. In. Assessing Tropical Forest Lands: Their suitability for sustainable uses. Carpenter, P.A. Ed. Tycool International. Dublin. pp. 105-139.

NAVEH, Z \& LIEBERMAN, A.S. (1984) Landscape Ecology: Theory and application. Springer Verlag. New York.

PASSOS, M.M DOS (1998) Biogeografia e Paisagem. FCT-UNESP/UFM. Presidente Prudente.

RAMALHO-FILHO, A. \& BEEK, K.J. (1995) Sistema de Avaliação da Aptidão Agrícola das Terras. EMBRAPA-CNPS. $3^{\text {a }}$ ed. Rio de Janeiro.

RAMALHO-FILHO, A., DE OLIVEIRA, R.P. \& PEREIRA, L.C. (1997) Use of geographic information systems in (planning) sustainable land management in Brazil: potentialities and user needs. ITC Journal 1997-3/4: 295-301.

RITERS, K.H., O’NEIL, R.V. \& JONES, K.B. (1997) Assessing habitat suitability at multiple scales: a landscape-level approach. Biol. Conservation 81: 191-202.

SALAS, G. DE LAS (1987) Suelos y Ecosistemas Forestales, con Emphasis en America Tropical. IICA. San Jose.

SAMPLE, V.A. (1994) Remote Sensing and GIS in Ecosystem Management. Island Press. Washington. 
SCHUGART, H.H. (1998) Terrestrial Ecosystems in Changing Environments. Cambridge Univ. Press. Cambridge,

SOTCHAVA, V.B. (1977) O estudo de geossistemas. Métodos em Questão 16. USP. São Paulo.

TRICART, J. \& KILLIAN, J. (1982) La Eco-Geografía y la Ordenación del Medio Natural. Ed. Anagrama. Barcelona.

TROLL, C. (1950) Die Geografishen Landschaft und ihre Erforschung. Studium Generale 3. Springer-Verlag. Berlin.

TROUBER, L., SMALING, E.M.A., ANDRIESSE, W. \& HAKKELING, R.T.A. (1989) Inventory and Evaluation of Tropical Forest Land. Tropenbos Tech. Series, 4. Ede.

TURNER, M.G. \& GARDNER, R.H. (1991) Quantitative Methods in Landscape Ecology. Springer-Verlag. New York.

UNESCO (1973) International Cartography and Classification of Vegetation. Ecology and Conservation 6. Paris.

VAN GILS, H.A.M.J. (1989) Legends of landscape ecology maps. ITC Journal 19891: 41-48.

VAN GILS, H.S.M.J. \& VAN WIJNGAARDEN, W. (1984) Vegetation structure in reconnaissance and semi-detailed vegetation surveys. ITC Journal 1984-3: 213218.

VELOSO, H.P., RANGEL-FILHO, A.L.R. \& LIMA, J.C.A. (1991) Classificação da Vegetação Brasileira, Adaptada a um Sistema Universal. FIBGE. Rio de Janeiro.

VINK, A.P.A. (1983) Landscape Ecology and Land Use. Longman. London.

WALTER, H. (1985) Vegetation of the Earth and Ecological Systems of the Geobiosphere. $3^{\text {rd }}$ Ed. Springer-Verlag. Heidelberg.

WEILL, M. DE A. M. (1990) Metodologias de avaliação de terras para fins agrícolas. R. bras. Geogr. 52: 127-160.

ZONNEVELD, I.S \& SURASANA, E. (1988) Ecosystem inventory/vegetation survey. ITC Journal 1988-1: 67-75.

ZONNEVELD, I.S. (1995) Land Ecology. SPB. Academic Publish. Amsterdam. 